\title{
Eating frequency and risk of colorectal cancer
}

\author{
Martine M. Perrigue, PhD, RD, \\ Cancer Prevention Program, Fred Hutchinson Cancer Research Center, 1100 Fairview Ave N., \\ Mailbox M4-B402, Seattle WA 98109 (USA), (206)-667-4760, fax: (206) 667-7850. Nutritional \\ Sciences Program, University of Washington, Seattle WA \\ Elizabeth D. Kantor, PhD, \\ Cancer Prevention Program, Fred Hutchinson Cancer Research Center, Seattle WA. Department \\ of Epidemiology, University of Washington, Seattle WA \\ Theresa A. Hastert, PhD, \\ Cancer Prevention Program, Fred Hutchinson Cancer Research Center, Seattle, WA. \\ Department of Epidemiology, University of Washington, Seattle WA \\ Ruth E. Patterson, PhD, \\ Moores Cancer Center, University of California San Diego, La Jolla, CA \\ John D. Potter, MD, PhD, \\ Division of Public Health Sciences, Fred Hutchinson Cancer Research Center, Seattle WA. \\ Department of Epidemiology, University of Washington, Seattle WA. Centre for Public Health \\ Research, Massey University, Wellington NEW ZEALAND \\ Marian L. Neuhouser, PhD, RD, and \\ Cancer Prevention Program, Fred Hutchinson Cancer Research Center, Seattle WA. Department \\ of Epidemiology, University of Washington, Seattle, WA. Nutritional Sciences Program, University \\ of Washington, Seattle WA
}

Emily White, PhD

Cancer Prevention Program, Fred Hutchinson Cancer Research Center, Seattle WA. Department of Epidemiology, University of Washington, Seattle, WA

Martine M. Perrigue: mperrigu@fhcrc.org

\section{Abstract}

Purpose-Eating frequency is a modifiable aspect of dietary behavior that may affect risk of colorectal cancer (CRC). Although most previous case-control studies indicate a positive association, two prospective studies suggest an inverse association between eating frequency and CRC risk, with evidence of effect modification by diet composition. We examined the association between eating frequency and CRC in a large, prospective cohort study, and explored whether this relationship was modified by sex, coffee consumption or dietary glycemic load.

Methods-Between 2000 and 2002, 67,912 western Washington residents aged 50-76 reported average daily meal and snack frequency using a mailed questionnaire as part of the VITamins And Lifestyle (VITAL) study. Participants were followed for CRC through linkage with SEER through 2008, over which time 409 CRC cases developed. Hazard Ratios and 95\% Confidence Intervals were obtained using Cox regression.

Correspondence to: Martine M. Perrigue, mperrigu@ fhcrc.org.

CONFLICT OF INTEREST STATEMENT

The authors declare that they have no conflict of interest. 
Results-In age and sex adjusted models higher (5+ times/d) vs lower (1-2 times/d) eating frequency was associated with a HR of $0.62\left(95 \%\right.$ CI $\left.0.43-0.88, \mathrm{P}_{\text {trend }}=0.001\right)$. However, following further adjustment for BMI, race/ethnicity, alcohol and other known CRC risk factors the relationship was no longer statistically significant (HR: 0.76; 95\% CI: 0.51, 1.14). No effect modification was observed by sex $\left(\mathrm{P}_{\text {interaction }}=0.45\right)$, coffee consumption $\left(\mathrm{P}_{\text {interaction }}=0.44\right)$ or dietary glycemic load $\left(\mathrm{P}_{\text {interaction }}=0.90\right)$. In subgroup analyses by tumor site, higher vs. lower eating frequency was associated with lower risk for colon (HR 0.65 95\% CI 0.39-1.07, $\left.\mathrm{P}_{\text {trend }}=0.04\right)$, but not rectal cancers $\left(\mathrm{HR}=1.0895 \%\right.$ CI 0.54-2.18, $\left.\mathrm{P}_{\text {trend }}=0.94\right)$.

Conclusion-The weak inverse association observed between eating frequency and CRC is consistent with findings from other prospective studies. Modification of this relationship by diet quality and participant characteristics should be considered in future studies.

\section{Keywords}

Eating frequency; meal frequency; nutrition; colorectal cancer

\section{INTRODUCTION}

Colorectal cancer (CRC) is the third most common cancer among men and women in the United States (1). Multiple dietary and lifestyle factors are recognized as determinants of CRC risk (2). Among these various dietary strategies, eating frequency has been identified from several lines of biological evidence as a modifiable aspect of dietary behavior that may influence risk of CRC (3). However, the eating frequency data are not consistent and there is no clear consensus from which to formulate eating pattern recommendations. One of the earliest hypotheses associating higher eating frequency with colorectal cancer has centered on the more frequent postprandial secretion of bile acids into the gut lumen that occurs with habitual frequent eating. It is thought that the bile acids subsequently induce bacterial production of tumorigenic secondary bile acids (4). In support of this hypothesis, some studies have found an inverse relationship between eating frequency and serum cholesterol, possibly due to increased bile acid secretion when food is more frequently consumed (5). Bile acid metabolism may be more likely to impact tumor growth in the colon vs. the rectum, given resorption of bile acids in the proximal colon (6). Other studies have shown that specific foods components may modify the eating frequency-bile acid-colorectal cancer relationship. For example, since coffee consumption decreases bile acid secretion and fecal transit time, coffee may modify the association between eating frequency and CRC risk (7). Another plausible mechanism to support the eating frequency-colorectal cancer relationship is that more frequent food consumption may lead to a state of chronic low-grade inflammation due to slight, but constant, elevations in pro-inflammatory metabolic substrates and hormones (8), potentially increasing CRC risk. Clearly, these relationships are complex.

In contrast to the evidence suggesting that higher eating frequency increases CRC risk, there is also biological rationale to support the hypothesis that increased eating frequency would decrease CRC risk. First, diabetes and insulin resistance are associated with increased CRC risk $(9,10)$. Both hyperglycemia and hyperinsulinemia can stimulate increased production of the mitogenic protein Insulin-like Growth Factor-I (IGF-I) by the liver (11). In the colon, IGF-I halts apoptosis and promotes cell proliferation and tumor growth (12). A dietary pattern characterized by several small, frequent meals may attenuate postprandial spikes in blood glucose and insulin and may help moderate production of IGF-I, thus limiting proliferation of tumor cells in the colon and rectum (11). In addition, the overall glycemic effect and quantity of carbohydrates consumed, as reflected by the dietary glycemic load (GL) is positively associated with risk for CRC (13), and dietary GL may modify the association between eating frequency and CRC via its influence on concentrations of blood 
glucose and insulin $(14,15)$. Although the majority of case-control studies have suggested a positive relationship between eating frequency and risk for CRC $(3,4,16-23)$, only a few prospective cohort studies have been published. Tseng et al. examined data from NHANES and reported a borderline-significant inverse association between eating frequency with colorectal cancer risk (24). Similarly, Mekary et al. observed an inverse association among subgroups defined by diet quality among participants in the Health Professionals Follow-up Study (25). Because the prospective cohort data to date are somewhat limited, we examined the association of eating frequency with risk of CRC in a large prospective cohort study of older males and females residing in western Washington State. Further, we sought to determine whether this relationship was modified by specific dietary components (coffee consumption or glycemic load), and whether there was a difference in association across anatomic subsite (colon vs. rectum) or gender differences in the associations.

\section{MATERIALS AND METHODS}

\section{Study Population}

The study population includes participants of the VITamins And Lifestyle (VITAL) Study, a prospective cohort of persons aged 50-76 years residing in the 13-county Western Washington catchment area of the Surveillance, Epidemiology, and End Results (SEER) cancer registry (26). Using names purchased by a commercial mailing list, 364,418 potential participants were mailed a 24-page questionnaire and reminder postcard between October 2000 and November 2002. 77,719 respondents (21.3\%) completed the questionnaire and were deemed eligible for inclusion in the cohort. The comprehensive self-reported questionnaire included items on health history, demographic characteristics, as well as personal habits such as smoking and physical activity, weight, height, dietary supplement use and diet. Study procedures were approved by the Fred Hutchinson Cancer Research Center Institutional Review Board.

Participants with a history of CRC at baseline $(\mathrm{n}=971)$ were excluded from analyses, as were persons for whom history of CRC was missing $(\mathrm{n}=213)$. We also excluded persons with history of ulcerative colitis, Crohn's disease $(n=1030)$, and intestinal polyposis $(n=273)$. Additional exclusion criteria were: history of malabsorptive syndromes $(\mathrm{n}=42)$, diagnosis with in situ CRC over the course of follow-up (surveillance bias) $(\mathrm{n}=12)$, cancer noted on death certificate only $(n=1)$, and diagnosis with CRC of certain rare morphologies $(n=33)$, including malignant carcinoid tumors and lymphomas. We further excluded individuals with a history of diabetes $(n=5315)$, given the increased potential for altered eating frequency related to blood glucose management, and because diabetes is associated with increased CRC risk $(9,10)$. The above-listed exclusions were not mutually exclusive. After making these exclusions, we further excluded persons with less than one year of follow-up $(n=1031$, including 64 cases). Participants entered the analysis one year after baseline, and therefore all persons with less than one year of follow-up were dropped from the analyses in order to reduce the possibility of reverse causality in which symptoms of undiagnosed disease may have affected behavior. We then further excluded 1056 persons missing information on our exposure of interest, eating frequency, yielding a final sample of 67,912 persons, of whom 409 were diagnosed with colon or rectal cancer in an average of 5.8 years of follow-up.

\section{Exposure}

Eating frequency was ascertained by the question "On average, how many times a day did you eat (meals plus snacks)? Snacks include food, milk and milk beverages such as lattes. Coffee, tea and soft drinks alone do not count as snacks" with defined response options of up to $7+$ times per day. In the following analyses, these responses were collapsed to 1-2; 3; 4 ; and 5+ meals or snacks per day. 


\section{Follow-up for Colorectal Cancer and Censoring}

Cases include 409 incident, invasive cancers of the colon and rectum (ICD-O-3 codes 18 , 18.1-18.9, 19.9, and 20.9) (27), identified by linkage to the western Washington SEER registry. SEER cases are identified by area hospitals, state death certificates, and through offices of oncologists, radiologists, and pathologists, with information collected including anatomic subsite and histology. The VITAL dataset and SEER are linked annually in a largely automated process, with datasets matched on items common to both, such as name, Social Security number, and date of birth. If too few data items are in common to ensure a match, the datasets are reviewed manually, with participants telephoned directly if a match cannot be confirmed after manual inspection.

Participants were followed until date of CRC diagnosis (for cases), while non-cases were censored at the earliest of: date of death (6.7\%); date of migration out of the SEER catchment area (5.5\%); date of requested removal from study $(0.03 \%)$; or December $31^{\text {st }}$, $2008(87.8 \%)$. Deaths occurring within the state of Washington were identified by linkage to the state death file, while migrations out of area were identified by linkage to the National Change of Address system and by active follow-up involving telephone calls and mailings.

\section{Covariates}

Data on covariates were gathered using the VITAL questionnaire (26). Age and sex were included in all analyses. Multivariate analyses also included the following additional covariates selected a priori on the basis of being associated with CRC risk: race/ethnicity; educational status; BMI, physical activity; energy intake; total calcium intake; vitamin D intake; dietary fiber intake; alcohol consumption; fruit and vegetable intake; red and processed meat intake; and aspirin and non-aspirin NSAID use. Analyses also included adjustment for family history of CRC among $1^{\text {st }}$ degree relatives (yes/no); and receipt of sigmoidoscopy and/or colonoscopy in the 10 years prior to baseline (yes/no). Given the expected collinearity between dietary glycemic load and dietary fiber intake, no adjustment was made for dietary fiber intake in analysis of effect modification by glycemic load.

BMI (measured in $\mathrm{kg} / \mathrm{m}^{2}$ ) was calculated from self-reported height and weight at baseline. 1,114 persons were missing baseline BMI but reported height and weight at age 45 . For persons in this group, we estimated baseline BMI by first calculating the average BMI change per year since age 45 within sex-, age-, and race/ethnicity-specific groups among those with complete data, after which we applied the group-specific average BMI change per year to the number of years elapsing between baseline and age 45 .

Dietary intake was assessed using a food frequency questionnaire (FFQ) adapted from the Women's Health Initiative (28). This FFQ captures frequency of consumption and serving size of 120 foods and beverages in the year prior to baseline, with serving size defined as small, medium, or large in reference to a listed serving size specific to each sex.

Participants' FFQ data were dropped if they did not complete all pages of the FFQ or if they reported abnormally high or low energy intake (men reporting $<800 \mathrm{kcal} / \mathrm{day}$ or $>5000 \mathrm{kcal} /$ day; women reporting $<600 \mathrm{kcal} /$ day or $>4000 \mathrm{kcal} / \mathrm{day})(29)$. Coffee consumption was defined in terms of serving-size adjusted frequency of coffee drinks per week and did not include milk-based coffee drinks such as lattes and mochas. Dietary glycemic load (defined using available carbohydrate) was also calculated from the FFQ (30).

\section{Statistical Analysis}

Cox proportional hazards regression was used to estimate hazard ratios (HRs) and corresponding 95\% confidence intervals (CIs) between eating frequency and CRC risk, with age used as the time metric for analysis. Participants entered the analysis one year after 
completing the baseline questionnaire and exited at age of CRC diagnosis or censoring event. All exposures and covariates were modeled using categorical variables. Where applicable, we also present tests for trend. To assess the presence of trend, these categorical variables were instead modeled as ordinal variables (where levels of exposure correspond to $1,2,3$, etc.), with the P-value from the Wald test corresponding to the P-for-trend.

We tested for effect modification of the association between eating frequency and CRC by sex, coffee consumption (above/below median of 7 cups/week) and glycemic load (above/ below median of 96.0). A single interaction term was used to test for each interaction, corresponding to the cross-product between eating frequency (modeled as the trend variable) and either sex, coffee consumption or glycemic load. We also tested for differences in association across anatomic subsite (colon vs. rectum). To test for subsite-specific associations, we used Cox regression models with the case definition limited to cancers of a specific subsite; in these analyses, cancers of the subsite not under study were censored at date of diagnosis. For example, in analyses of colon cancer, rectal cancers were censored at the date of rectal cancer diagnosis. Logistic regression limited to cases was used to assess the statistical significance of subsite-specific differences. All tests are two-sided with $\mathrm{p}<0.05$ considered statistically significant and all analyses were conducted using Stata (version 12, College Station, TX).

\section{RESULTS}

Table 1 gives participant characteristics by eating frequency. Compared to respondents who reported eating less than 3 times per day, persons eating more than 3 times per day were more likely to be women, under the age of 60 , college-educated, physically active and to have never smoked. Compared with those who ate fewer than 3 times per day, those who ate 3 times per day or more were more likely to be in the highest quartiles of calcium intake; dietary fiber intake; and fruit and vegetable consumption. BMI (Table 1) as well as alcohol and red meat intake; aspirin and non-aspirin NSAID use; family history of CRC; and receipt of colonoscopy or sigmoidoscopy in the 10 years before baseline (data not shown) did not vary substantially by eating frequency. Table 2 gives hazard ratios (HRs) and 95\% confidence intervals (CIs) for CRC associated with eating frequency. In age- and sexadjusted models, eating frequency was inversely associated with CRC risk $\left(\mathrm{P}_{\text {trend }}=0.001\right)$, with eating 4 or more times per day associated with a $28-38 \%$ reduction in CRC risk compared with eating fewer than 3 times per day (HR for eating 4 times/day: 0.72, 95\% CI: 0.55-0.94; HR for eating 5+ times/day: $0.62,95 \%$ CI: $0.43-0.88$ ). These associations were not significant in multivariable-adjusted models (HR for eating 4 times/day: 0.81, 95\% CI: 0.59-1.11; HR for eating 5+ times/day: 0.76, 95\% CI: 0.51-1.14; $\left.\mathrm{P}_{\text {trend }}=0.08\right)$. Associations between eating frequency and CRC risk stratified by coffee consumption and glycemic load are given in Table 3. Eating frequency was inversely associated with CRC among women $\left(\mathrm{P}_{\text {trend }}=0.05\right)$, but not men, and no interaction was detected. We observed no effect modification of the association between eating frequency and colorectal cancer by either coffee consumption or dietary glycemic load.

Associations between eating frequency and CRC stratified by anatomic subsite are given in Table 4. Eating more frequently was associated with reduced risk of colon cancer $\left(\mathrm{P}_{\text {trend }}=0.04\right)$, but was not associated with rectal cancer $\left(\mathrm{P}_{\text {trend }}=0.94\right)$; however, these associations did not differ from one another statistically $\left(\mathrm{P}_{\text {interaction }}=0.22\right)$.

\section{DISCUSSION}

Using data from a large prospective cohort study, we observed a non-significant inverse relationship between eating frequency and risk for $\mathrm{CRC}\left(\mathrm{P}_{\text {trend }}=0.08\right.$ in multivariate- 
adjusted models), with those eating 4 or 5+ times per day having a 19-24\% reduced risk of CRC compared to those eating 1-2 times a day. This relationship was not modified by sex, coffee consumption or dietary glycemic load in multivariate models $\left(P_{\text {interaction }}=0.45,0.44\right.$, 0.90 , respectively). Higher eating frequency was associated with statistically significantly lower risk for colon cancer $\left(\mathrm{P}_{\text {trend }}=0.04\right)$, but no relationship was observed between eating frequency and risk of rectal cancer $\left(\mathrm{P}_{\text {trend }}=0.94\right)$; although these subsite-specific differences were not statistically significant $\left(\mathrm{P}_{\text {difference }}=0.22\right)$.

The majority of previous case-control studies have observed a positive relationship between eating frequency and CRC $(3,4,16-20,22,23)$. However, the case-control design is subject to recall bias, and it is possible that diagnosis or symptoms influenced actual eating behavior or recall of eating frequency in cases in these studies. In contrast to these findings, prospective data from two studies $(24,25)$ and the present investigation suggest the possibility of an inverse relationship between eating frequency and CRC risk. Using data from 9,978 subjects in the Epidemiologic Follow-Up Study of the First National Health and Nutrition Examination Survey (NHEFS-NHANES), Tseng and colleagues found a nonsignificant inverse relationship between eating frequency and CRC risk such that CRC risk was $34 \%$ lower in participants who ate 3 or 4 times per day as compared to those who ate fewer than 3 times per day (relative risk: 0.66 , 95\% CI: $0.42-1.03$ ). This relationship was driven by increased meal, rather than snack frequency (24). In a more recent study conducted among 34,968 men within the Health Professionals Follow-up Study, Mekary and colleagues found no overall association between eating frequency and risk of CRC, with eating frequency defined by total meals and snacks (25).

It is clear that qualities of the diet are important to consider in studies of eating frequency and CRC risk. Studies of eating frequency have employed a wide variety of definitions for "meals" and "snacks," leading to difficulty in interpretation of findings and limiting comparisons between studies. Persons consuming a greater number of "snacks" may have higher risk for CRC due to lower dietary quality, as "snack-type" foods such as chips, cookies and pastries. These foods generally have higher glycemic index than foods consumed at regular meals, and thus more frequent snack consumption could increase dietary glycemic load. Using data from the VITAL cohort study, we were unable to parse apart "meals" from "snacks," but we were able to examine whether the association between total eating frequency and CRC was modified by dietary glycemic load and observed no such effect modification $\left(\mathrm{P}_{\text {interaction }}=0.90\right)$. Although we found no effect modification by these measures (coffee consumption and dietary glycemic load), Mekary and colleagues observed that higher eating frequency was associated with lower risk for CRC in participants with a higher diet quality (reflected by higher DASH score $(31))\left(\mathrm{P}_{\text {interaction }}=0.01\right)$ and among those with expected high insulin sensitivity, as defined by consumption of $>2$ servings of coffee per day, being physically active, and BMI $<25 \mathrm{~kg} / \mathrm{m}^{2}\left(\mathrm{P}_{\text {interaction }}<0.01\right.$, (25).

The present study has several strengths. Recall bias is unlikely to affect results in a prospective study where future disease status is unknown at baseline. Additionally, use of the SEER cancer registry for identification of CRC cases likely contributed to a high level of accuracy in outcome ascertainment. However, this study is not without limitation. Dietary intake questions were designed to measure consumption patterns occurring during the previous year. It is possible that exposures earlier in life may have had a greater influence over development of CRC than the dietary patterns assessed at ages 50-76. Frequency of eating was defined as the combined total of number of eating occasions per day, and intake of "meals" and "snacks" as separate types of eating occasion was not examined. Although this limits our ability to compare findings with those of some previous investigations, the terms "meal" and "snack" lack standard definitions, so between-studies comparisons would 
not likely yield meaningful conclusions. Also, the current analysis did not employ a variable representative of overall diet quality such as the DASH score, limiting our ability to compare our findings to those of Mekary et al (25). The number of cases $(n=409)$ in the present study is relatively small, particularly rectal cancer cases $(n=81)$, in comparison to other studies on colorectal cancer. Furthermore, power may be limited in subgroup analyses, potentially limiting our ability to detect significant differences across subgroups. Pooling data from several large cohorts may be warranted to ascertain sufficient numbers of rectal cancer cases to better address this important question.

Findings from the present study add to the body of literature indicating that the frequency of daily eating occasions may be an important factor that should be considered alongside total energy and nutrient content when evaluating the health effects of a given dietary pattern. In future investigations, scientists would benefit from the use of clearly defined terms for "meals" and "snacks", as could be obtained from objective measurements from intervention studies. Analysis of diet quality would help to determine further factors that may modify the relationship between eating frequency and CRC. Results from randomized clinical trials would also help determine whether there is an optimal eating frequency (perhaps related to exercise patterns or body fat distribution) and to formulate appropriate strategies for incorporating this behavior into daily life.

\section{Acknowledgments}

This work was supported by grant K05CA154337 from the National Cancer Institute (NCI) and Office of Dietary Supplements and grant R25CA094880 from NCI.

\section{References}

1. Jemal A, Siegel R, Xu J, et al. Cancer Statistics, 2010. Cancer J Clin. 2010; 60(5):277-300.

2. Chan AT, Giovannucci EL. Colon Cancer: An Update and Future D. Primary Prevention of Colorectal Cancer. Gastroenterology. 2010; 138(6):2029-43. e10. [PubMed: 20420944]

3. Coates AO, Potter JD, Caan BJ, et al. Eating frequency and the risk of colon cancer. Nutr Cancer. 2002; 43(2):121-6. [PubMed: 12588690]

4. Potter JD, McMichael AJ. Diet and cancer of the colon and rectum: a case-control study. J Natl Cancer Inst. 1986; 76(4):557-69. [PubMed: 3007842]

5. Giovannucci E. Insulin and Colon Cancer. Cancer Cause Control. 1995; 6(2):164-79.

6. McMichael AJ, Potter JD. Host factors in carcinogenesis: certain bile-acid metabolic profiles that selectively increase the risk of proximal colon cancer. J Natl Cancer Inst. 1985; 75(2):185-91. [PubMed: 3894750]

7. Tavani A, Vecchia CL. Coffee, Decaffeinated Coffee, Tea and Cancer of the Colon and Rectum: A Review of Epidemiological Studies, 1990-2003. Cancer Cause Control. 2004; 15(8):743-57.

8. Esposito K, Giugliano D. Diet and inflammation: a link to metabolic and cardiovascular diseases. Eur Heart J. 2006; 27(1):15. [PubMed: 16219650]

9. Luo W, Cao Y, Liao C, et al. Diabetes mellitus and the incidence and mortality of colorectal cancer: a meta-analysis of 24 cohort studies. Colorectal Dis. 2012; 14(11):1307-12. [PubMed: 23046351]

10. Wu L, Yu C, Jiang H, et al. Diabetes Mellitus and the Occurrence of Colorectal Cancer: An Updated Meta-Analysis of Cohort Studies. Diabetes Technol Ther. 2013; 15(5):419-427. [PubMed: 23540566]

11. Houston, MS.; Holly, JMP.; Feldman, EL. IGF and Nutrition in Health and Disease. Totowa, N.J: Humana Press; 2005.

12. Sandhu MS, Dunger DB, Giovannucci EL. Insulin, Insulin-Like Growth Factor-I (IGF-I), IGF Binding Proteins, Their Biologic Interactions, and Colorectal Cancer. J Natl Cancer Inst. 2002; 94(13):972-80. [PubMed: 12096082]

13. Gnagnarella P, Gandini S, Maisonneuve P, et al. Glycemic index, glycemic load, and cancer risk: A meta-analysis. Am J Clin Nutr. 2008; 87(6):1793-801. [PubMed: 18541570] 
14. Mekary RA. Eating patterns and type 2 diabetes risk in men: breakfast omission, eating frequency, and snacking. Am J Clin Nutr. 2012; 95(5):1182-9. [PubMed: 22456660]

15. Mekary RA, Giovannucci E, Cahill L, et al. Eating patterns and type 2 diabetes risk in older women: breakfast consumption and eating frequency. Am J Clin Nutr. 2013; 98(2):436-43. [PubMed: 23761483]

16. Benito E, Obrador A, Stiggelbout A, et al. A population-based case-control study of colorectal cancer in Majorca. I. Dietary factors. Int J Cancer. 1990; 45(1):69-76. [PubMed: 2298506]

17. Young TB, Wolf DA. Case-control study of proximal and distal colon cancer and diet in Wisconsin. Int J Cancer. 1988; 42(2):167-75. [PubMed: 3403062]

18. Favero A, Franceschi S, La Vecchia C, et al. Meal frequency and coffee intake in colon cancer. Nutr Cancer. 1998; 30(3):182-5. [PubMed: 9631488]

19. Franceschi S, La Vecchia C, Bidoli E, et al. Meal frequency and risk of colorectal cancer. Cancer Res. 1992; 52(13):3589-92. [PubMed: 1617629]

20. de Verdier MG, Longnecker MP. Eating Frequency: A Neglected Risk Factor for Colon Cancer? Cancer Cause Control. 1992; 3(1):77-81.

21. La Vecchia C, Ferraroni M, Mezzetti M, et al. Attributable risks for colorectal cancer in northern Italy. Int J Cancer. 1996; 66(1):60-4. [PubMed: 8608968]

22. Shoff SM, Newcomb PA, Longnecker MP. Frequency of eating and risk of colorectal cancer in women. Nutr Cancer. 1997; 27(1):22-5. [PubMed: 8970177]

23. Wei JT, Connelly AE, Satia JA, et al. Eating frequency and colon cancer risk. Nutr Cancer. 2004; 50(1):16-22. [PubMed: 15572293]

24. Tseng M, Ingram DD, Darden R, et al. Eating frequency and risk of colorectal cancer. Nutr Cancer. 2000; 36(2):170-6. [PubMed: 10890027]

25. Mekary RA, Hu FB, Willett WC, et al. The Joint Association of Eating Frequency and Diet Quality With Colorectal Cancer Risk in the Health Professionals Follow-up Study. Am J Epidemiol. 2012; 175(7):664-72. [PubMed: 22387430]

26. White E, Patterson RE, Kristal AR, et al. VITamins And Lifestyle cohort study: study design and characteristics of supplement users. Am J Epidemiol. 2004; 159(1):83-93. [PubMed: 14693663]

27. Fritz, A.; Percy, C.; Jack, A., et al., editors. International Classification of Diseases for Oncology. Geneva: World Health Organization; 2000.

28. Patterson RE, Kristal AR, Tinker LF, et al. Measurement characteristics of the Women's Health Initiative food frequency questionnaire. Ann Epidemiol. 1999; 9(3):178-87. [PubMed: 10192650]

29. Willett, W. Nutritional Epidemiology. 2. New York: Oxford Universal Press; 1998.

30. Neuhouser ML, Tinker L, Thomson C, et al. Development of a glycemic index database for food frequency questionnaires used in epidemiologic studies. J Nutr. 2006; 136:1604-9. [PubMed: 16702328]

31. Sacks FM, Svetkey LP, Vollmer WM, et al. Effects on blood pressure of reduced dietary sodium and the Dietary Approaches to Stop Hypertension (DASH) diet. DASH-Sodium Collaborative Research Group. N Engl J Med. 2001; 344(1):3-10. [PubMed: 11136953] 
Table 1

VITAL Study participant characteristics by eating frequency

\begin{tabular}{|c|c|c|c|}
\hline & $\begin{array}{c}\text { Eat }<3 x / \text { day } \\
n=14,801 \\
n(\%)\end{array}$ & $\begin{array}{c}\text { Eat 3x/day } \\
\mathrm{n}=\mathbf{2 0 , 9 1 3} \\
n(\%)\end{array}$ & $\begin{array}{c}\text { Eat }>\text { 3x/day } \\
\mathrm{n}=\mathbf{3 2 , 1 9 8} \\
n(\%)\end{array}$ \\
\hline \multicolumn{4}{|l|}{ Age at Baseline (years) } \\
\hline $50-<55$ & 3,185 (21.5) & 4,297 (20.6) & $9,099(28.3)$ \\
\hline $55-<60$ & $3,259(22.0)$ & $4,590(22.0)$ & $7,959(24.7)$ \\
\hline $60-<65$ & $2,846(19.2)$ & $3,764(18.0)$ & $5,733(17.8)$ \\
\hline $65-<70$ & $2,530(17.1)$ & $3,666(17.5)$ & $4,561(14.2)$ \\
\hline $70+$ & $2,981(20.1)$ & $4,596(22.0)$ & $4,846(15.1)$ \\
\hline \multicolumn{4}{|l|}{ Sex } \\
\hline Female & $6,857(46.3)$ & $9,453(45.2)$ & $19,312(60.0)$ \\
\hline Male & $7,944(53.7)$ & $11,460(54.8)$ & $12,886(40.0)$ \\
\hline \multicolumn{4}{|l|}{ Race } \\
\hline White & $13,149(90.5)$ & $19,210(93.4)$ & $30,188(95.0)$ \\
\hline Hispanic & $184(1.27)$ & $158(0.77)$ & $219(0.69)$ \\
\hline Black & $382(2.63)$ & $224(1.09)$ & $174(0.55)$ \\
\hline American Indian/Alaska Native & $277(1.91)$ & $259(1.26)$ & $384(1.21)$ \\
\hline Asian or Pacific Islander & $417(2.87)$ & $580(2.82)$ & $651(2.05)$ \\
\hline Other & $114(0.78)$ & $139(0.68)$ & $157(0.49)$ \\
\hline \multicolumn{4}{|l|}{ Education } \\
\hline High School Graduate/GED or Less & $3,983(27.4)$ & $4,036(19.6)$ & $4,906(15.4)$ \\
\hline Some College/Technical School & $6,144(42.3)$ & $7,494(36.4)$ & $11,647(36.7)$ \\
\hline College Grad or Above & $4,402(30.3)$ & $9,039(43.9)$ & $15,216(47.9)$ \\
\hline \multicolumn{4}{|l|}{ Body Mass Index $\left(\mathrm{kg} / \mathrm{m}^{2}\right)$} \\
\hline Normal Weight $(<25)$ & $4,852(34.0)$ & $7,384(36.4)$ & $11,253(35.9)$ \\
\hline Overweight $(\geq 25-<30)$ & $6,222(43.6)$ & $8,765(43.2)$ & $12,595(40.1)$ \\
\hline Obese $(\geq 30-<35)$ & $2,336(16.4)$ & $2,976(14.7)$ & $5,062(16.1)$ \\
\hline Severely Obese ( $\mathbf{3 5}$ ) & $857(6.01)$ & $1,162(5.73)$ & $2,481(7.90)$ \\
\hline \multicolumn{4}{|l|}{ Physical Activity (MET-hrs per week mod/vig activity) ${ }^{a}$} \\
\hline None & $8,309(57.0)$ & $10,576(51.3)$ & $14,954(47.0)$ \\
\hline Tertile 1 & $2,317(15.9)$ & $3,378(16.4)$ & $5,460(17.2)$ \\
\hline Tertile 2 & $2,087(14.3)$ & $3,310(16.1)$ & $5,590(17.6)$ \\
\hline Tertile 3 & $1,873(12.8)$ & $3,362(16.3)$ & $5,820(18.3)$ \\
\hline \multicolumn{4}{|l|}{ Smoking Status } \\
\hline Never Smoker & $5,988(41.1)$ & $9,832(47.5)$ & $16,783(52.6)$ \\
\hline Former Smoker (Quit 10+ Years Before Baseline) & $2,200(15.1)$ & $1,739(8.40)$ & $1,710(5.36)$ \\
\hline Former Smoker (Quit <10 Years Before Baseline) & $1,153(7.90)$ & $1,336(6.46)$ & $1,852(5.80)$ \\
\hline Current Smoker & $5,247(36.0)$ & 7,787 (37.6) & $11,587(36.3)$ \\
\hline
\end{tabular}




\begin{tabular}{|c|c|c|c|}
\hline & $\begin{array}{c}\text { Eat }<3 \mathrm{3x} / \mathrm{day} \\
\mathrm{n}=\mathbf{1 4 , 8 0 1} \\
n(\%)\end{array}$ & $\begin{array}{c}\text { Eat 3x/day } \\
\text { n= 20,913 } \\
n(\%)\end{array}$ & $\begin{array}{c}\text { Eat }>3 x / \text { day } \\
n=32,198 \\
n(\%)\end{array}$ \\
\hline \multicolumn{4}{|c|}{ Calcium Intake (Diet + Supplemental) (mg/day) } \\
\hline Quartile 1: $<728$ & $4,387(34.4)$ & $5,147(27.1)$ & $5,877(19.5)$ \\
\hline Quartile 2: $728<1041$ & $3,207(25.1)$ & $4,964(26.2)$ & $7,287(24.2)$ \\
\hline Quartile 3: 1041-1467 & $2,731(21.4)$ & $4,593(24.2)$ & $8,163(27.1)$ \\
\hline Quartile 4: 1467+ & $2,439(19.1)$ & $4,281(22.6)$ & $8,780(29.2)$ \\
\hline \multicolumn{4}{|l|}{ Dietary Fiber Intake (g/day) } \\
\hline Quartile 1: $<12.4$ & $4,452(34.6)$ & $4,969(26.0)$ & $6,099(20.1)$ \\
\hline Quartile 2: $12.4-<17.4$ & $3,292(25.6)$ & $4,904(25.7)$ & $7,357(24.3)$ \\
\hline Quartile 3: $17.4-<23.6$ & $2,785(21.7)$ & $4,790(25.1)$ & $7,987(26.4)$ \\
\hline Quartile 4: 23.6+ & $2,331(18.1)$ & $4,425(23.2)$ & $8,847(29.2)$ \\
\hline \multicolumn{4}{|c|}{ Fruit/Vegetable Intake (Excl. Potatoes) (servings/day) } \\
\hline Quartile 1: $<2.05$ & $4,511(35.1)$ & $5,030(26.4)$ & $5,980(19.7)$ \\
\hline Quartile 2: $2.05-<3.17$ & $3,414(26.6)$ & $5,114(26.8)$ & $7,029(23.2)$ \\
\hline Quartile 3: $3.17-<4.81$ & $2,709(21.1)$ & $4,840(25.4)$ & $8,030(26.5)$ \\
\hline Quartile 4: 4.81+ & $2,226(17.3)$ & $4,104(21.5)$ & $9,251(30.5)$ \\
\hline
\end{tabular}

${ }^{a}$ Tertiles of physical activity among those engaging in moderate/vigorous leisure time physical activity determined within gender: women (T1: $>0$ $<2.8, \mathrm{~T} 2: 2.8-<9.5, \mathrm{~T} 3: 9.5+)$, men (T1: $>0-<4.4, \mathrm{~T} 2: 4.4-<13.5, \mathrm{~T} 3: 13.5+)$

${ }^{b}$ Use of aspirin (including both low-dose and regular aspirin) and non-aspirin NSAID defined by use over 10 years prior to baseline, with low use defined as use $<4$ days per week or $<4$ years, and high use defined as $4+$ days per week for $4+$ years 


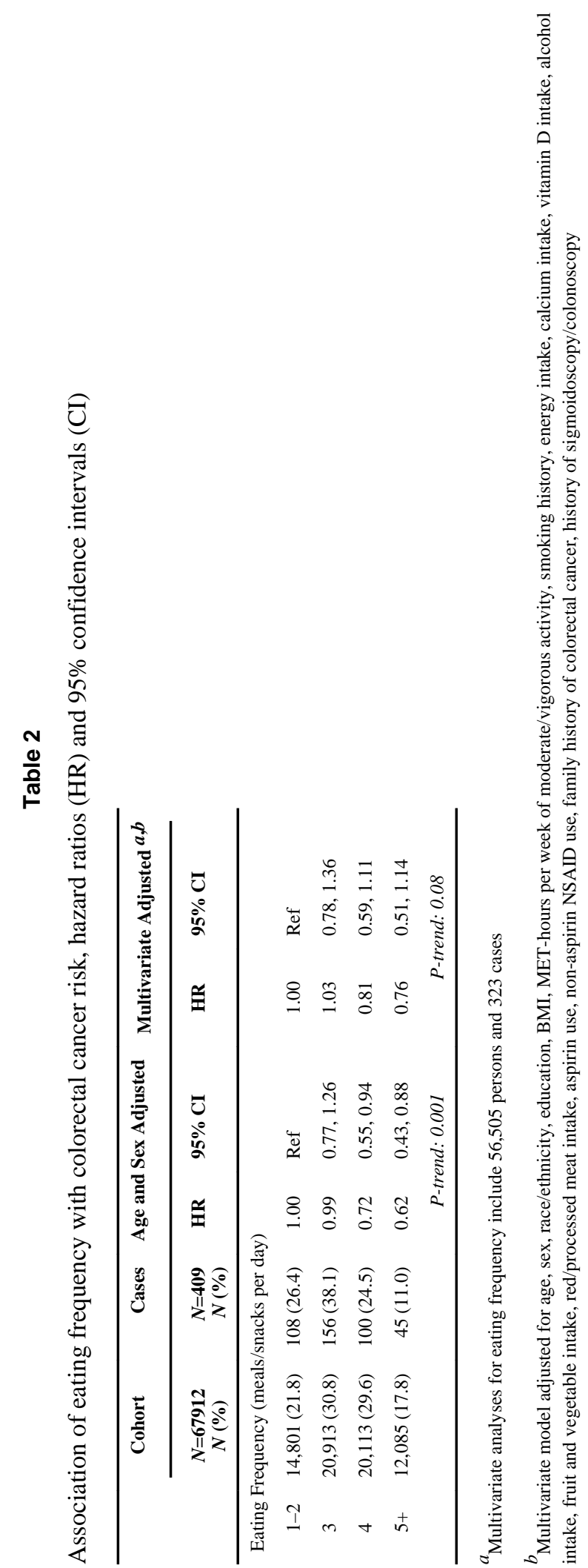




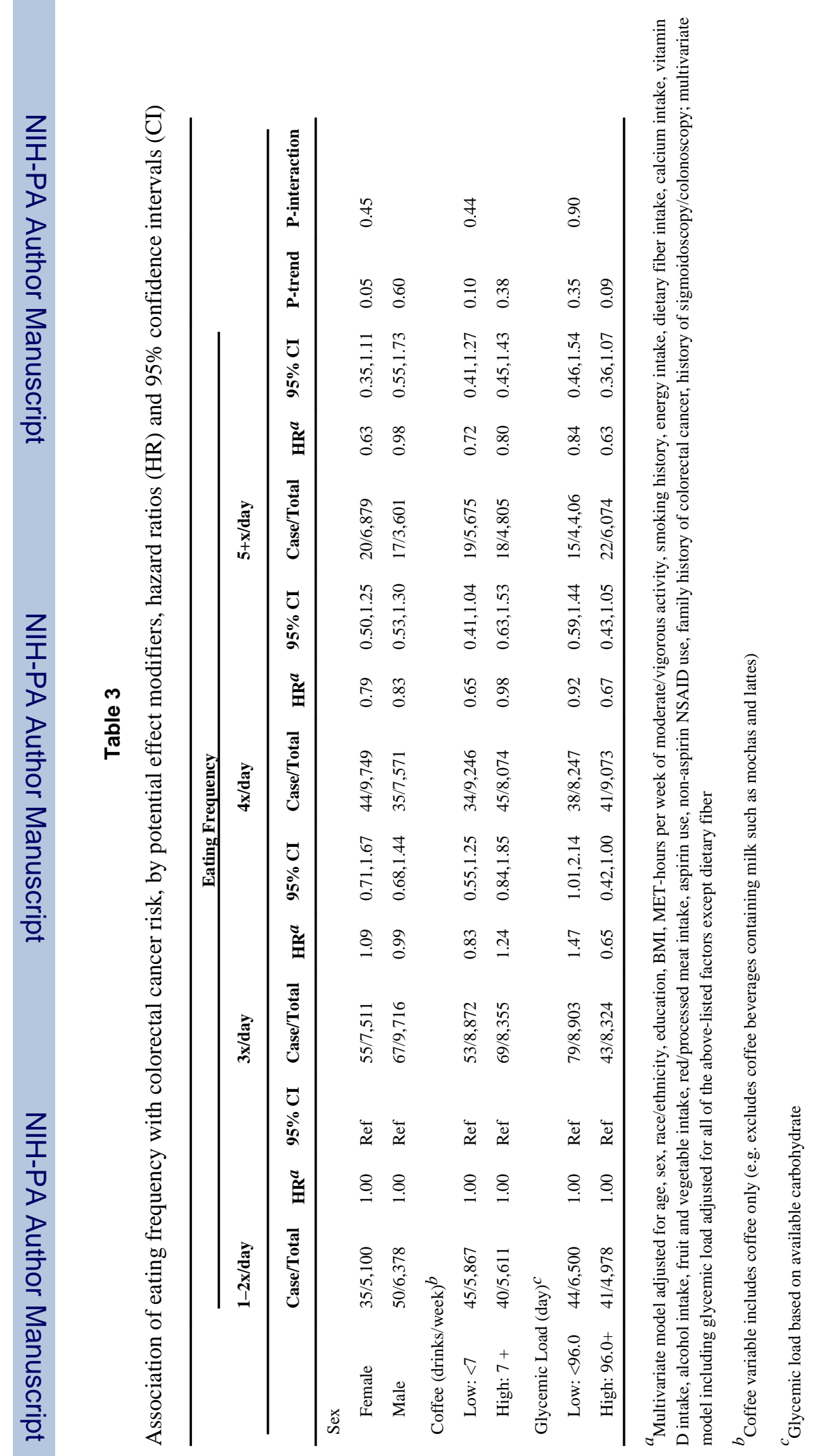

Cancer Causes Control. Author manuscript; available in PMC 2014 December 01. 


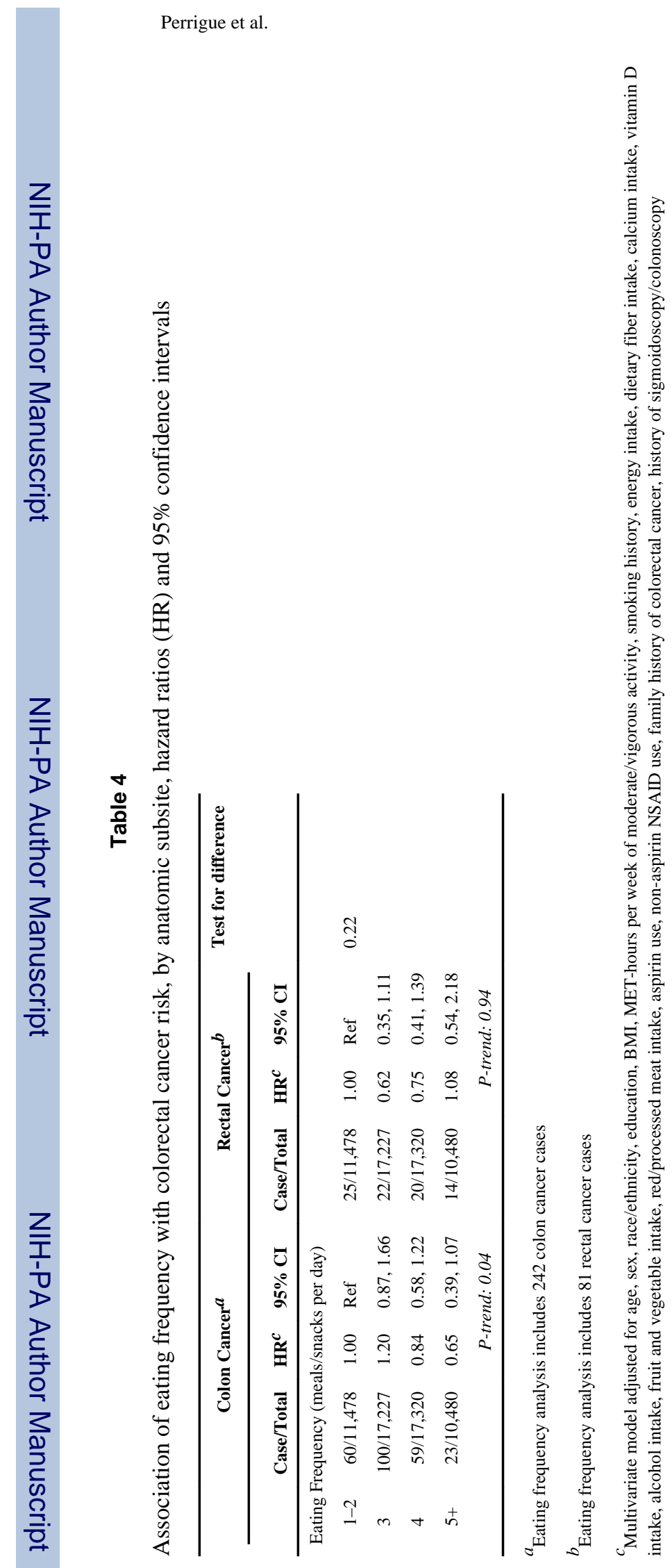

Cancer Causes Control. Author manuscript; available in PMC 2014 December 01. 